\title{
Positive and negative early life experiences differentially modulate long term survival and amyloid protein levels in a mouse model of Alzheimer's disease
}

\author{
Sylvie L. Lesuis ${ }^{1}$, Herve Maurin ${ }^{2}$, Peter Borghgraef ${ }^{2}$, Paul J. Lucassen ${ }^{1}$, Fred Van \\ Leuven $^{2}$ and Harm J. Krugers ${ }^{1}$ \\ ${ }^{1}$ Swammerdam Institute for Life Sciences, Center for Neuroscience, University of Amsterdam, Amsterdam, The Netherlands \\ 2 Experimental Genetics Group - LEGTEGG, Department of Human Genetics, KU Leuven, Leuven, Belgium \\ Correspondence to: Sylvie L. Lesuis, email: S.L.Lesuis@uva.nl \\ Keywords: early life stress, early handling, biAT, Alzheimer, glucocorticoids, Gerotarget \\ Received: March 28, $2016 \quad$ Accepted: May 12, $2016 \quad$ Published: June 01, 2016
}

\section{ABSTRACT}

Stress has been implicated as a risk factor for the severity and progression of sporadic Alzheimer's disease (AD). Early life experiences determine stress responsivity in later life, and modulate age-dependent cognitive decline. Therefore, we examined whether early life experiences influence AD outcome in a bigenic mouse model which progressively develops combined tau and amyloid pathology (biAT mice).

Mice were subjected to either early life stress (ELS) or to 'positive' early handling (EH) postnatally (from day 2 to 9 ). In biAT mice, ELS significantly compromised long term survival, in contrast to EH which increased life expectancy. In 4 month old mice, ELS-reared biAT mice displayed increased hippocampal A $\beta$ levels, while these levels were reduced in EH-reared biAT mice. No effects of ELS or EH were observed on the brain levels of APP, protein tau, or PSD-95. Dendritic morphology was moderately affected after ELS and EH in the amygdala and medial prefrontal cortex, while object recognition memory and open field performance were not affected. We conclude that despite the strong transgenic background, early life experiences significantly modulate the life expectancy of biAT mice. Parallel changes in hippocampal A $\beta$ levels were evident, without affecting cognition of young adult biAT mice.

\section{INTRODUCTION}

Alzheimer's disease (AD) is a neurodegenerative disorder characterised by progressive impairments in cognitive functions [1]. Prominent neuropathological features of $\mathrm{AD}$ are amyloid-containing plaques and neurofibrillary tauopathy consisting of threads and tangles (NFT), which are observed throughout the brain, including areas critically involved in memory formation and emotional regulation [2]. The accumulation of amyloid plaques and tauopathy is believed to underlie neuronal and synaptic dysfunction, and age-related cognitive decline [3, $4]$.

While genetics, in particular specific mutations, have been implicated in rare forms of familial dementia [5], the aetiology of the large majority of late-onset however, sporadic AD cases remains elusive. It has been hypothesised that gene-environment interactions, epigenetic factors, exercise, diet, stress, and life-style in general, contribute to the incidence and progression of late-onset sporadic AD [6, 7]. Epidemiological studies support a role for chronic stress as an important environmental risk factor for $\mathrm{AD}$ progression $[8,9]$. Indeed, elderly individuals that are prone to psychological distress are more likely to develop AD than non-stressed individuals of the same age [10]. Animal model studies substantiate this role of environmental modulation of AD. Chronic stress in adulthood e.g. elevates $A \beta_{40}$ and $\mathrm{A} \beta_{42}$ brain levels, accelerates amyloid plaque formation, increases tauopathy and neuronal atrophy, and impairs learning and memory in various mouse models [11-13].

Stress during the period of early life, when the brain is still developing, often has more pronounced exposure and longer lasting effects compared to adult stress. 
Moreover, early life stress not only enhances sensitivity of the brain to subsequent later stressors, but also accelerates age-related cognitive decline [14-19]. In contrast, daily handling $(\mathrm{EH})$ during the early postnatal period is known to increase maternal care, blunts the sensitivity to stressors later in life, and reduces age-related cognitive decline in wild type rodents $[14,20]$.

While early life experiences influence cognition later in life, it remains elusive whether they also affect the development of AD pathology and reduce life expectancy in AD models. We therefore imposed 'negative' versus 'positive' experiences during the early period from postnatal day (PND) 2-9 and analysed whether they differentially influenced AD-related brain changes in transgenic APP.V717I x Tau.P301L (biAT) mice. biAT mice are well characterised to develop both amyloid plaques and neurofibrillary tau pathology over time [21]. We examined the effects of ELS and EH in BiAT mice on (i) the life expectancy, (ii) amyloid levels and synaptic proteins in the brain, (iii) behavioural performance, and (iv) the dendritic architecture in brain areas relevant for memory formation.

\section{RESULTS}

\section{Body weight}

Housing litters in a cage with limited nesting and bedding material from PND 2-9 fragments maternal care and is a well-known model to elicit early life stress (ELS) in the offspring $[22,23]$. In our study, offspring of biAT mice that were stressed during early life showed a $15 \%$ reduction in body weight gain from PND 2-9, compared to control-reared litters from the same genetic background, $(\mathrm{t}(11)=2.96 ; p<0.05)($ Figure 1A).

In another group of biAT mice, the pups were separated from the dam daily for 15 minutes (early handling, EH) in the same PND 2-9 timeframe. This is known to enhance maternal care upon reunion of the dam with her pups and is a commonly used model for early life enhancement $[24,25]$. EH increased body weight gain significantly by $32 \%$ compared to control-reared mice $(\mathrm{t}(4)=-2.93 ; p<0.05)$ (Figure 1B).

When reaching adulthood, these differences in body weight were no longer evident between the four groups of biAT mice (data not shown).

\section{Life expectancy}

Even biAT mice reared under control conditions, are known to suffer severe mortality between age 6-8 weeks and adulthood [21] (Figure 2A). Interestingly, the survival rate of biAT mice that were stressed early in life was significantly lower compared to control biAT mice, . The survival in the ELS-group remained significantly lower until the end of the experiment $\left(\chi^{2}(1)=4.35 ; p<0.05\right)$. At P110, $40.3 \%$ of biAT control animals were still alive, while only $20.3 \%$ of the biAT animals that were exposed to ELS survived. Survival was not affected by ELS in Tau. P301L littermates during the same time window of this study $\left(\chi^{2}(1)=1.17\right.$, ns, Figure $\left.2 B\right)$.

In the EH-experiment we observed a similar early mortality of the biAT control animals (Figure 2C). Most interestingly, in contrast to ELS, the EH treatment significantly increased the life expectancy of biAT mice: $82.6 \%$ were still alive at PND 110 compared to only $46.7 \%$ of the control biAT animals $\left(\chi^{2}(1)=4.15 ; p\right.$ $<0.05$ ) (Figure 2C). Again, survival of the Tau.P301L littermates undergoing exactly the same treatment was not significantly affected $\left(\chi^{2}(1)=0.62\right.$, ns; Figure 2D). Given the strong effects of these early life experiences on life expectancy of the biAT mice, as opposed to the Tau.P301L littermates, all subsequent experiments were conducted in biAT mice.

\section{Hippocampal protein levels}

To investigate whether ELS and EH modified AD related hallmarks differentially, we quantified protein Tau phosphorylated at serine 202 and threonine 205 (the epitope defined by Mab AT8), the levels of the amyloid peptides and their precursor APP. In addition, we measured the levels of PSD-95, a major post-synaptic protein (Figure 3A). Western blot analysis of hippocampal homogenates from the biAT mice revealed that ELS significantly increased in the levels of soluble monomeric $\mathrm{A} \beta(\mathrm{t}(6)=-2.79, p<0.05)$, while the levels of APP $(\mathrm{t}(10)$ $=0.65, \mathrm{~ns})$, pTau at AT8 $(\mathrm{t}(9)=-1.38, \mathrm{~ns})$ and PSD-95 levels $(\mathrm{t}(1.05)=0.26, \mathrm{~ns})$ were not altered (Figure $3 \mathrm{~B})$. In contrast, $\mathrm{EH}$ reduced levels of soluble, monomeric $\mathrm{A} \beta$ in the hippocampus $(\mathrm{t}(5)=2.63, p<0.05)$, while again the APP $(\mathrm{t}(6)=1.80, \mathrm{~ns})$, pTau at AT8 $(\mathrm{t}(4)=-0.72, \mathrm{~ns})$ and PSD-95 levels $(\mathrm{t}(4)=0.20, \mathrm{~ns})$ were unaffected (Figure 3C).

\section{Anxiety and object recognition memory}

\section{Anxiety and locomotion}

To investigate general locomotion and anxiety-like behaviour in young adult mice (PND $90 \pm 3$ ), the open field test was conducted. Exposure of biAT mice to ELS did not affect anxiety-like behaviour as the time spent in the centre zone of the arena was not different between ELS and control raised biAT mice $(\mathrm{t}(12)=0.41$, ns) (Figure 4A). In addition, exposure to ELS did not affect the general level of activity as no differences were detected in the total distance travelled throughout the arena (Ctrl vs ELS: $\mathrm{t}(12)=0.86, \mathrm{~ns}$ ) (Figure 4C). Likewise, in biAT mice 

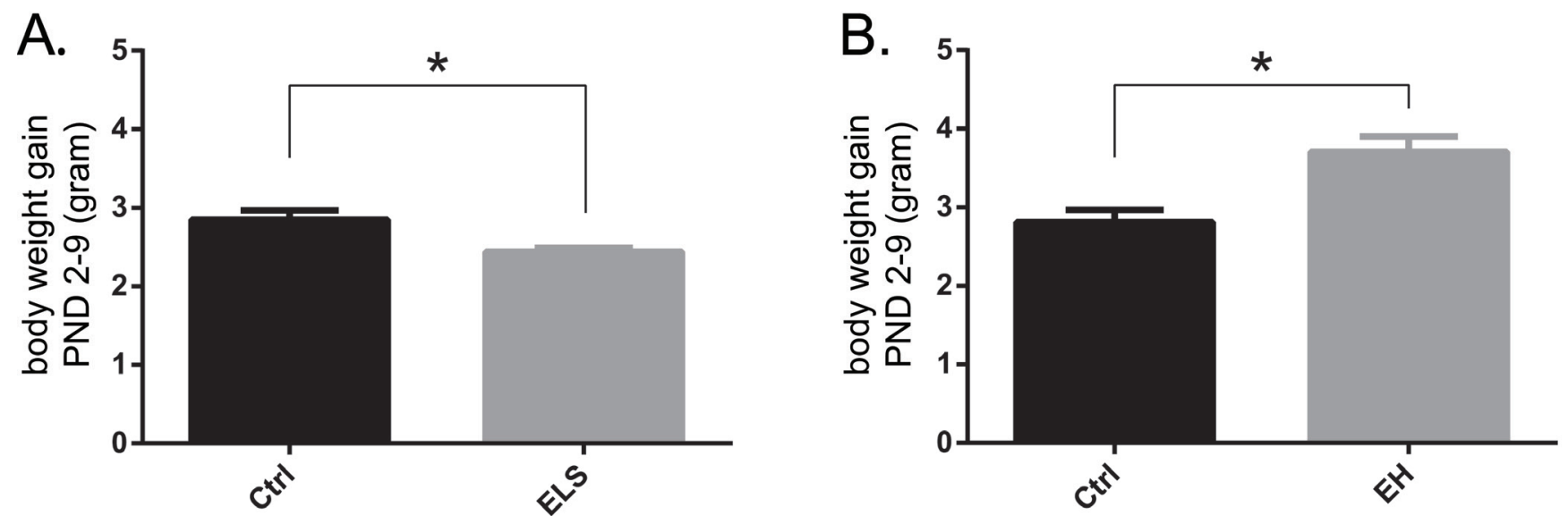

Figure 1: Early life experiences acutely affect body weight of biAT mice. Body weight gain measured from PND 2 and 9 in A. ELS litters (Ctrl: $n=7$; ELS: $n=7 ; \mathrm{t}(11)=2.96 ; p<0.05)$, and B. EH animals (Ctrl: $n=5$; EH: $n=4 ; \mathrm{t}(4)=-2.93 ; p<0.05)$ each compared to control reared biAT mice. Data are expressed as mean $\pm \mathrm{SEM}$.
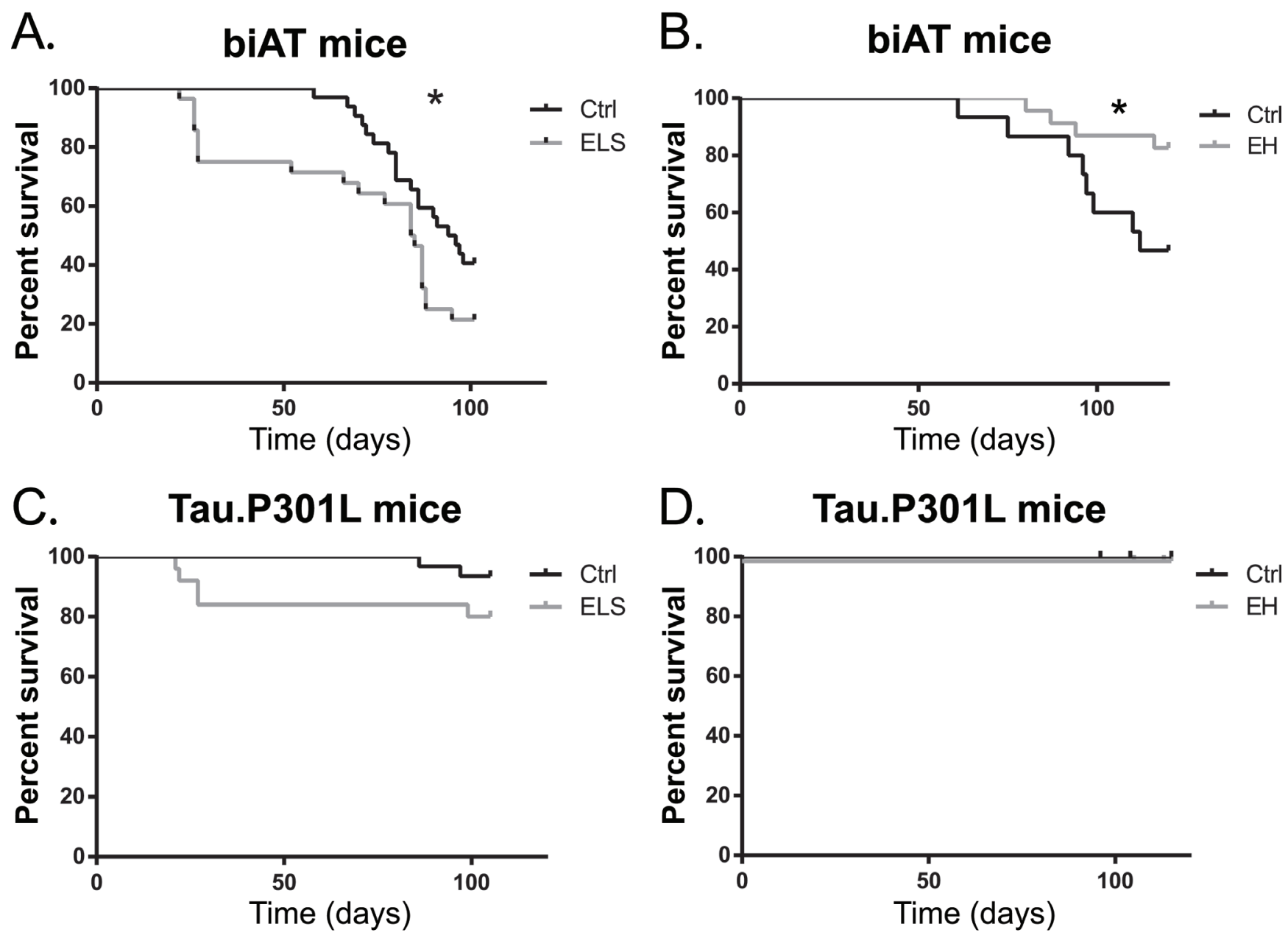

Figure 2: ELS exacerbates early death while EH prolongs survival of young biAT mice. A. ELS significantly decreased survival of biAT mice (Ctrl: $n=32$; ELS: $\left.n=28 ; \chi^{2}(1)=4.35 ; p<0.05\right)$. B. EH prolonged survival compared to control mice (Ctrl: $n=15$; $\left.\mathrm{EH}: n=23 ; \chi^{2}(1)=4.15 ; p<0.05\right)$. C. Tau.P301L littermates were not significantly affected by ELS $\left(\right.$ Ctrl: $n=31 ;$ ELS: $n=25 ; \chi^{2}(1)=1.17$, $\mathrm{ns})$ or D. by EH (Ctrl: $n=17$; EH: $n=6 ; \chi^{2}(1)=0.62$, ns). 
Table 1: Morphological alterations of the dendritic tree of neurons of subregions of the medial prefrontal cortex after ELS or EH in adult mice (PND 120)

\begin{tabular}{|c|c|c|c|c|c|c|}
\hline & & & Ctrl & ELS & Ctrl & EH \\
\hline \multirow{6}{*}{ 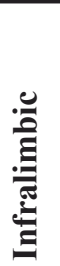 } & \multirow{3}{*}{ Basal } & Branch length $(\mu \mathrm{m})$ & $916 \pm 32$ & $651 \pm 126^{*}$ & $1253 \pm 113$ & $979 \pm 73^{*}$ \\
\hline & & DCI & $5415 \pm 264$ & $2662 \pm 963 * *$ & $5769 \pm 1017$ & $4477 \pm 419$ \\
\hline & & Branch points & $6.14 \pm 0.42$ & $3.83 \pm 1.01^{*}$ & $6.82 \pm 0.80$ & $6.28 \pm 0.46$ \\
\hline & \multirow{3}{*}{ Apical } & Branch length $(\mu \mathrm{m})$ & $476 \pm 93$ & $656 \pm 101$ & $603 \pm 85$ & $478 \pm 51$ \\
\hline & & DCI & $7556 \pm 1768$ & $18410 \pm 6607^{\$}$ & $37806 \pm 11205$ & $14485 \pm 2578$ \\
\hline & & Branch points & $3.00 \pm 0.32$ & $3.50 \pm 0.76$ & $5.58 \pm 0.72$ & $4.62 \pm 0.57$ \\
\hline \multirow{6}{*}{ 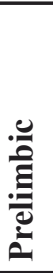 } & \multirow{3}{*}{ Basal } & Branch length $(\mu \mathrm{m})$ & $924 \pm 66$ & $1218 \pm 118^{*}$ & $1397 \pm 87$ & $1251 \pm 77$ \\
\hline & & DCI & $4938 \pm 428$ & $9007 \pm 2113^{*}$ & $8359 \pm 1428$ & $7854 \pm 850$ \\
\hline & & Branch points & $5.83 \pm 0.35$ & $7.9 \pm 0.70^{*}$ & $8.22 \pm 0.92$ & $8.76 \pm 0.54$ \\
\hline & \multirow{3}{*}{ Apical } & Branch length $(\mu \mathrm{m})$ & $469 \pm 65$ & $490 \pm 60$ & $733 \pm 83$ & $695 \pm 56$ \\
\hline & & DCI & $6848 \pm 1726$ & $13538 \pm 4768$ & $59072 \pm 13985$ & $56768 \pm 11618$ \\
\hline & & Branch points & $3.10 \pm 0.65$ & $3.1 \pm 0.75$ & $6.91 \pm 0.69$ & $6.91 \pm 0.66$ \\
\hline \multirow{6}{*}{ 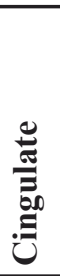 } & \multirow{3}{*}{ Basal } & Branch length $(\mu \mathrm{m})$ & $855 \pm 102$ & $960 \pm 66$ & $1400 \pm 72$ & $1438 \pm 111$ \\
\hline & & \begin{tabular}{|l|}
$\mathrm{DCI}$ \\
\end{tabular} & $7317 \pm 1941$ & $4496 \pm 667$ & $8292 \pm 719$ & $8433 \pm 1060$ \\
\hline & & Branch points & $7.47 \pm 1.12$ & $6.63 \pm 1.03$ & $8.46 \pm 0.50$ & $8.85 \pm 0.62$ \\
\hline & \multirow{3}{*}{ Apical } & Branch length $(\mu \mathrm{m})$ & $357 \pm 69$ & $316 \pm 51$ & $825 \pm 53$ & $665 \pm 95$ \\
\hline & & DCI & $3162 \pm 1131$ & $4256 \pm 2075$ & $70986 \pm 16210$ & $50530 \pm 13664$ \\
\hline & & Branch points & $2.47 \pm 0.72$ & $2.13 \pm 0.66$ & $7.91 \pm 0.84$ & $6.35 \pm 1.08$ \\
\hline
\end{tabular}

Values are presented as mean \pm SEM. Significance to its relative control group is indicated as follows: **: $p<0.01, *: p<$ $0.05, \$: p<0.1$.

EH had no effects on the time spent in the centre zone $(\mathrm{t}(35)=-0.70, \mathrm{~ns})$ (Figure 4B), nor on the total distance travelled $(\mathrm{t}(35)=-0.38, \mathrm{~ns})$ (Figure $4 \mathrm{D})$.

\section{Object recognition memory}

In biAT mice, cognitive performance, as assessed by explorative behaviour in the novel object recognition test (PND $91 \pm 3$ ), was not affected by either ELS or EH (Figure 4E, 4F). When exposed to two identical objects during the training trial all animals expressed equal amounts of sniffing behaviour towards both objects, indicating no preference for the location of the object (data not shown). In the testing trial, biAT mice exposed to ELS and control rearing discriminated between the familiar and novel object, with exploration percentages being significantly higher than 50\% (Ctrl: $\mathrm{t}(5)=17.99, p<$ 0.000; ELS: $\mathrm{t}(5)=3.16, p<0.05)$. However, no difference in the amount of exploration was observed between ELS and control biAT mice $(\mathrm{t}(5.58)=1.16$, ns) (Figure 4E). Likewise, all EH and control biAT mice displayed novel object exploration levels that were significantly higher than 50\% (Ctrl: $\mathrm{t}(15)=2.96, p<0.05$; EH: $\mathrm{t}(19)=4.60$, $p<0.000)$. No difference in exploration was observed between any of the groups $(\mathrm{t}(34)=0.43$, ns) (Figure 4F).

\section{Dendritic morphology}

\section{Medial prefrontal cortex (mPFC)}

We first examined dendritic morphology of neurons in the $\mathrm{mPFC}$, which has been shown to be sensitive to early life adversity [26]. The mPFC is involved in executive functions and short-term memory, although subregions of the mPFC may respond differently as the infralimbic, prelimbic, and cingulate cortex are functionally and structurally distinct [27]. Indeed, the length of the basal dendritic tree of pyramidal neurons in the infralimbic cortex was reduced both as a consequence of ELS and EH in biAT mice compared to their respective control groups (ELS vs Ctrl: $\mathrm{t}(7)=2.40, p<0.05$; EH $v s$ Ctrl: $\mathrm{t}(17)=2.42, p<0.05)$ (Table 1). Furthermore, after ELS exposure the dendritic complexity index (DCI) ( $t(7)$ $=3.73, p<0.05)$, and the number of branch points $(\mathrm{t}(7)$ $=2.56, p<0.05$ ) of the basal dendrites were significantly reduced in the infralimbic cortex. To further investigate the effects of early life environment on cellular morphology a segmental Sholl analysis was performed which examines changes in dendritic length as a function of radial distance from the soma. The reductions in basal branch length were, albeit mildly, reflected in the segmental distribution of the basal dendrites (Figure 5A, 5B) with a trend towards a reduction by both EH and ELS treatments compared to their respective controls (ELS $v s$ Ctrl: $\mathrm{F}(1,7)=5.11, p=$ 0.058; EH vs Ctrl: $\mathrm{F}(1,17)=4.31, p<0.05)$. No effect of either early life manipulation were reported on apical 

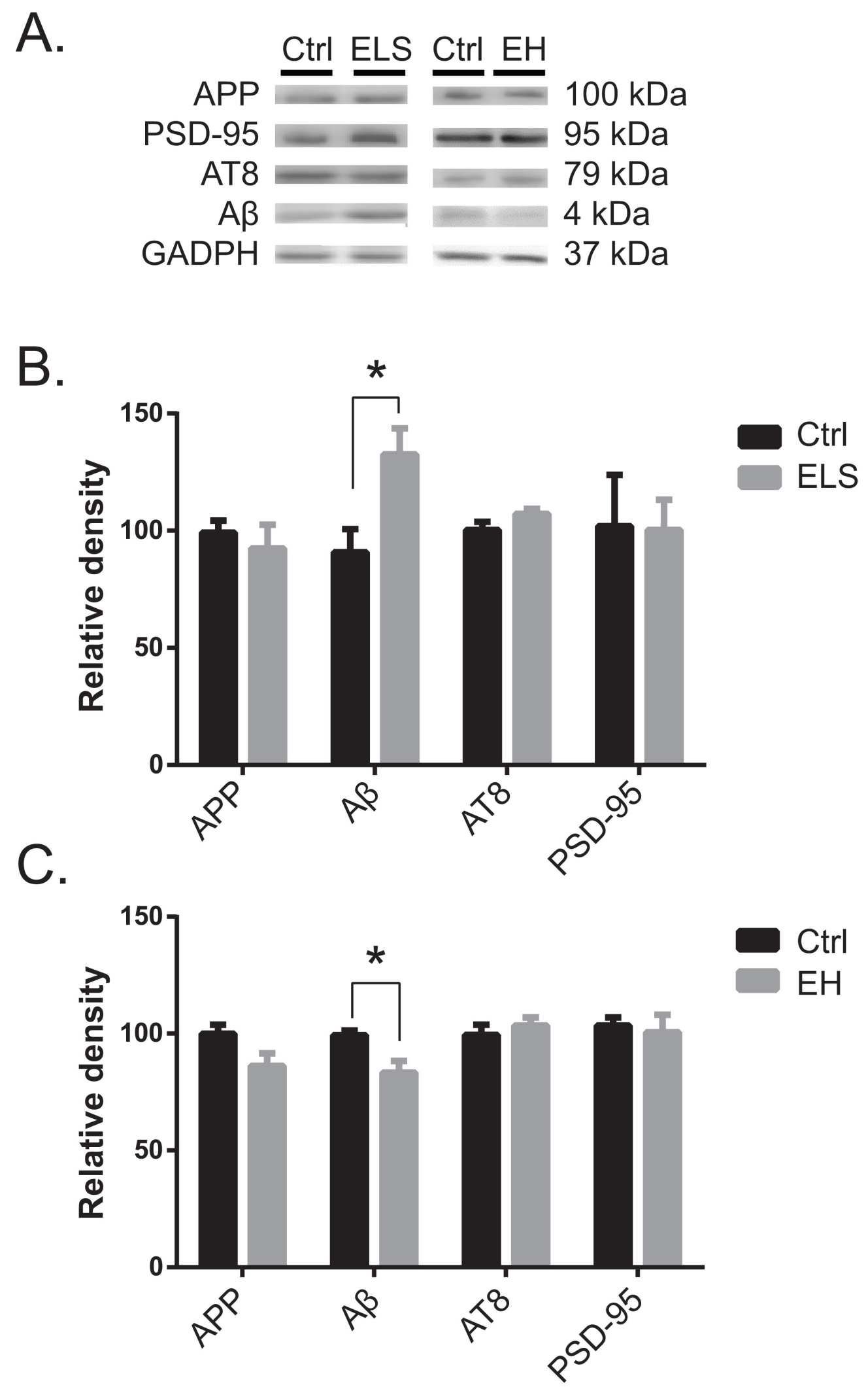

Figure 3: Early life experience alters hippocampal A $\beta$ levels at PND 120 in biAT mice. A. Western blot of hippocampal protein extracts demonstrated elevated A $\beta$ levels after ELS B., whereas EH led to a reduction in A $\beta$ levels. C.. No effects of ELS or EH were observed on levels of APP. B. protein tau (AT8) C. or PSD-95 (H,I). ELS vs Ctrl, Ctrl: $n=7$, ELS: $n=5$; EH vs Ctrl, Ctrl: $n=3$, EH: $n=5$. Data are expressed as mean \pm SEM. 


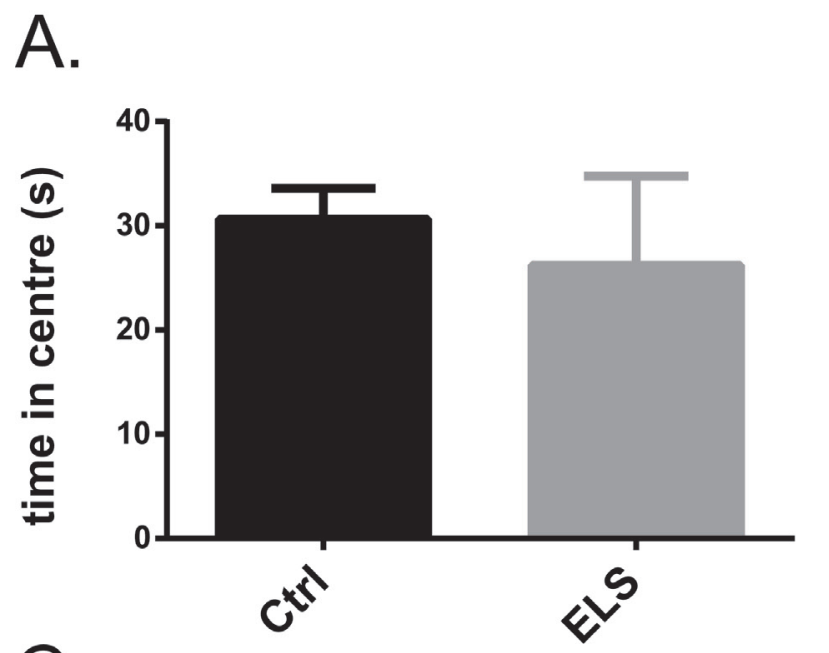

B.
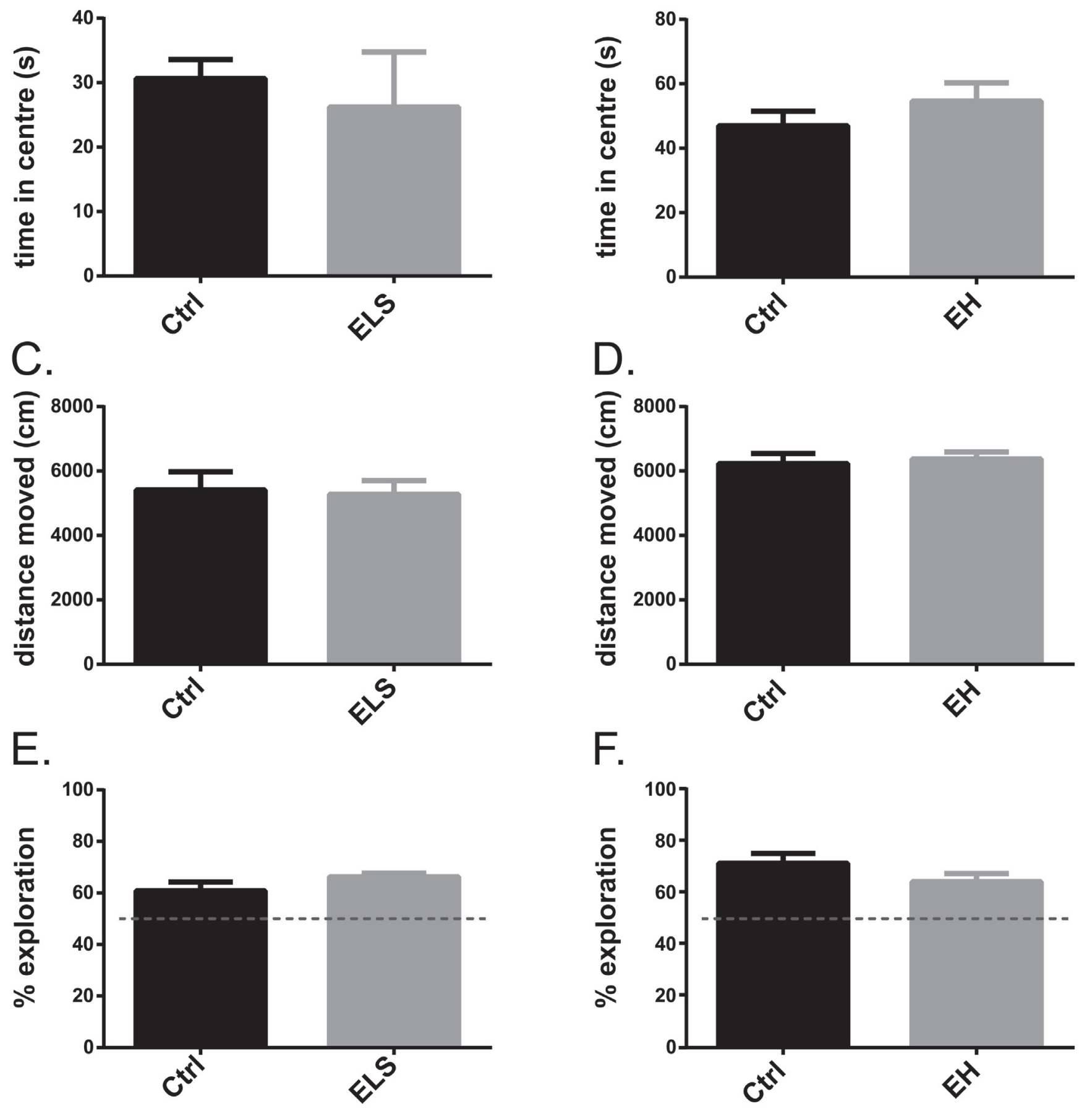

Figure 4: Explorative behaviour and cognition was not affected by early life experiences. Time spent in the centre of the open field was not significantly different between ELS and Ctrl biAT $(\mathrm{t}(12)=0.41, \mathrm{~ns})$. A. or EH and Ctrl biAT mice $(\mathrm{t}(35)=-0.70$, ns. B. Total locomotor activity was also resistant to either ELS (Ctrl vs ELS: $\mathrm{t}(12)=0.86$, ns) C. or EH (Ctrl vs EH: $\mathrm{t}(35)=-0.38$, ns). D. . Although all groups explored the novel object significantly above chance level $(\mathrm{Ctrl} v s$ ELS experiment: $\mathrm{Ctrl}$ : $\mathrm{t}(5)=17.99, p<0.000$; ELS: $\mathrm{t}(5)=$ 3.16, $p<0.05$; Ctrl vs EH experiment: Ctrl: $\mathrm{t}(15)=2.96, p<0.05$; $\mathrm{EH}: \mathrm{t}(19)=4.60, p<0.000)$ cognitive performance was comparable for all groups $\left(\mathrm{Ctrl} v s\right.$ ELS: $\mathrm{t}(5.58)=1.16, \mathrm{~ns}$; Ctrl $v_{s} \mathrm{EH}: \mathrm{t}(34)=0.43$, ns). E.,F.. ELS vs Ctrl: Ctrl: $n=7$, ELS: $n=7$; EH $v s$ Ctrl: Ctrl: $n=15$, $\mathrm{EH}: n=21$. Data are expressed as mean $\pm \mathrm{SEM}$. 
A. Infralimbic cortex - basal

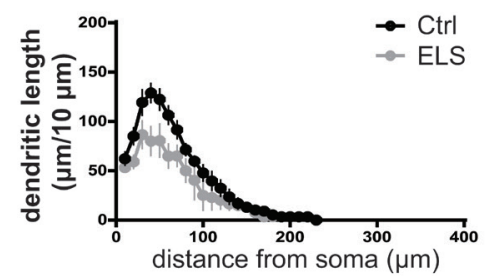

C. Infralimbic cortex - apical

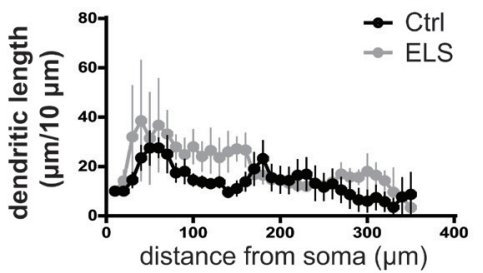

E. Prelimbic cortex - basal

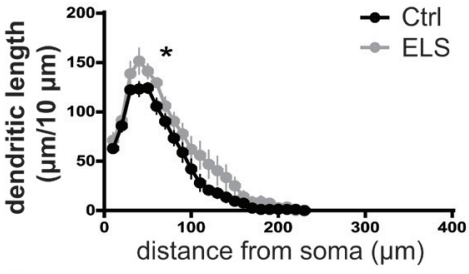

G. Prelimbic cortex - apical

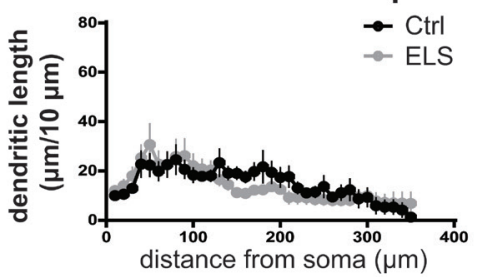

I. Cingluate cortex - basal

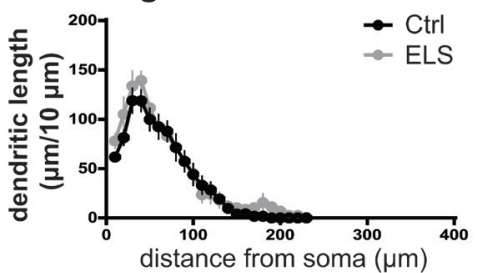

K. Cingulate cortex - apical

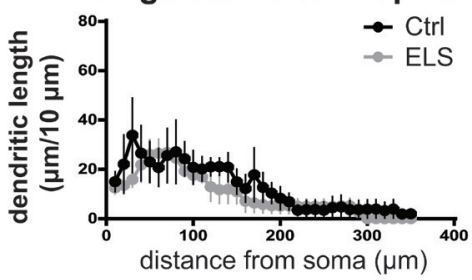

B. Infralimbic cortex - basal

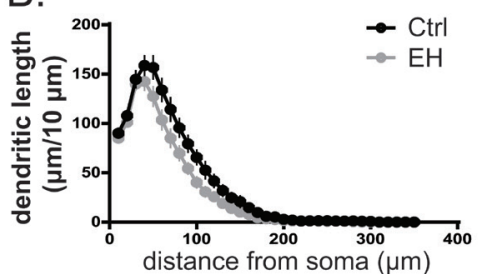

D. Infralimbic cortex - apical

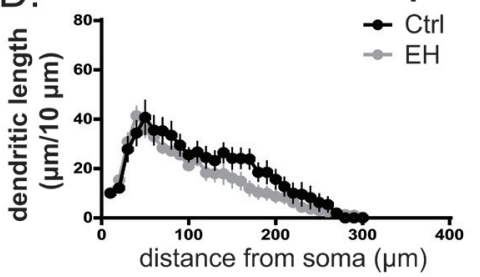

F. Prelimbic cortex - basal

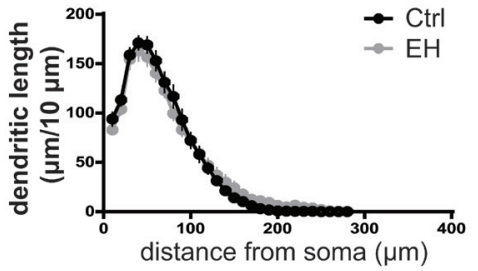

H. Prelimbic cortex - apical

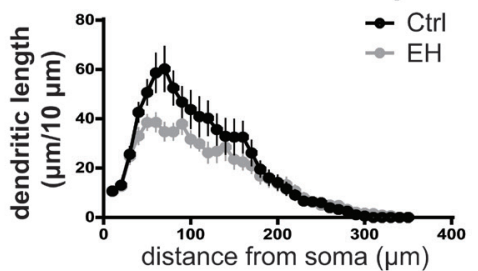

J. Cingulate cortex - basal

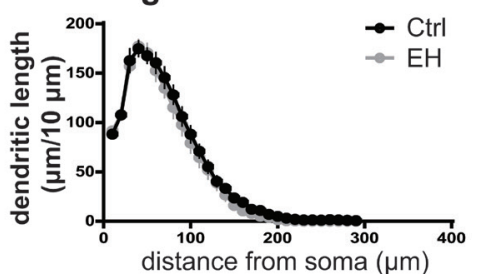

L. Cingulate cortex - apical

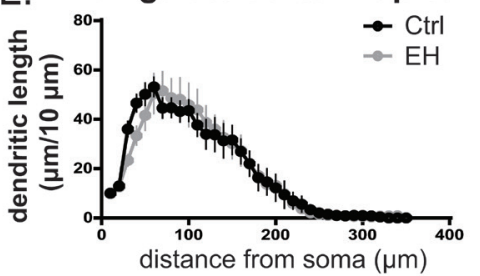

Figure 5: Dendritic morphology of mPFC subregions is differentially affected by ELS and EH. Sholl plots of the distribution of apical and basal dendritic length at increasing distances from the centre of the cell body. In the basal dendrites of the infralimbic cortex, a trend towards a reduction in dendritic distribution was observed after both ELS and EH (ELS vs Ctrl: $\mathrm{F}(1,7)=5.11, p=0.058$; EH vs Ctrl: $\mathrm{F}(1,17)=4.31, p<0.05)$. A.,B.. In the infralimbic cortex no effects of ELS or EH were reported on apical dendrites C.,D.. As a consequence of ELS, basal dendritic distribution of the prelimbic area was increased $(\mathrm{F}(1,11)=4.92, p<0.05)$, with significant post hoc differences at $60 \mu \mathrm{m}$ from the centre of the cell body $\mathbf{E}$.. No effects were observed in basal dendritic distribution in the prelimbic area after EH F.. The apical branches of the prelimbic cortex were not different between ELS and EH animals and their respective controls G.,H.. In the cingulate cortex, dendritic length at increasing distance from the centre of the cell body is comparable between ELS and Ctrl I.,K. and between EH and Ctrl J.,L. for both the apical and basal tree. 3-5 neurons from one animal were averaged (3-12 animals/group). Data are expressed as mean \pm SEM. 
Table 2: Morphological alterations of the dendritic tree of stellate neurons of the basolateral nucleus of the amygdala after ELS and EH in adult mice (PND 120)

\begin{tabular}{|c|c|c|c|c|c|}
\hline & & Ctrl & ELS & Ctrl & EH \\
\hline \multirow{3}{*}{ 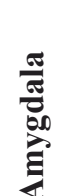 } & Branch length $(\mu \mathrm{m})$ & $941 \pm 42$ & $1204 \pm 139^{*}$ & $1203 \pm 57$ & $1200 \pm 88$ \\
\hline & DCI & $5837 \pm 667$ & $9209 \pm 3526$ & $12300 \pm 1244$ & $11441 \pm 2375$ \\
\hline & Branch points & $8.02 \pm 0.28$ & $8.78 \pm 1.61$ & $8.78 \pm 0.69$ & $8.41 \pm 0.84$ \\
\hline
\end{tabular}

Values are presented as mean \pm SEM. Significance to its relative control group is indicated as follows: $*: p<0.05$.

Table 3: Morphological alterations of the dendritic tree of hippocampal CA1 and CA3 pyramidal neurons after ELS or EH in adult mice (PND 120)

\begin{tabular}{|c|c|c|c|c|c|c|}
\hline & & & Ctrl & ELS & Ctrl & $\overline{\mathbf{E H}}$ \\
\hline & & Branch length $(\mu \mathrm{m})$ & $1017 \pm 94$ & $945 \pm 56$ & $541 \pm 58$ & $574 \pm 45$ \\
\hline & Basal & DCI & $25036 \pm 3443$ & $28390 \pm 3429$ & $6191 \pm 1499$ & $7061 \pm 887$ \\
\hline & & Branch points & $9.81 \pm 0.85$ & $9.85 \pm 0.55$ & $4.88 \pm 0.51$ & $5.48 \pm 0.36$ \\
\hline & & Branch length $(\mu \mathrm{m})$ & $1557 \pm 103$ & $1440 \pm 160$ & $1239 \pm 80$ & $1380 \pm 100$ \\
\hline 7 & Apical & $\overline{\mathrm{DCI}}$ & $442479 \pm 69835$ & $410175 \pm 92073$ & $198886 \pm 35130$ & $242883 \pm 33503$ \\
\hline ن & & Branch points & $17.19 \pm 1.15$ & $15.55 \pm 1.95$ & $13.01 \pm 1.35$ & $13.92 \pm 1.12$ \\
\hline & & Branch length $(\mu \mathrm{m})$ & $879 \pm 128$ & $821 \pm 83$ & $339 \pm 39$ & $323 \pm 24$ \\
\hline & Basal & $\overline{\mathrm{DCI}}$ & $8226 \pm 2932$ & $14579 \pm 3586$ & $1728 \pm 316.69$ & $1573 \pm 305$ \\
\hline & & Branch points & $5.61 \pm 0.85$ & $8.23 \pm 1.58$ & $1.96 \pm 0.26$ & $1.66 \pm 0.19$ \\
\hline & & Branch length $(\mu \mathrm{m})$ & $614 \pm 91$ & $524 \pm 30$ & $551 \pm 36$ & $592 \pm 39$ \\
\hline$m$ & Apical & DCI & $24140 \pm 7983$ & $13473 \pm 429$ & $12338 \pm 2100$ & $15090 \pm 2286$ \\
\hline U & & Branch points & $4.97 \pm 0.97$ & $4.07 \pm 0.22$ & $3.60 \pm 0.36$ & $4.01 \pm 0.32$ \\
\hline
\end{tabular}

Values are presented as mean \pm SEM. Significance to its relative control group is indicated as follows: $*: p<0.05$.

dendrites of the infralimbic cortex (Figure 5C, 5D).

In the basal tree of pyramidal neurons of the prelimbic cortex, ELS significantly increased the dendritic branch length $(\mathrm{t}(10)=-2.61, p<0.05)$, the DCI $(\mathrm{t}(9)=$ $-3.69, p<0.05)$, and the number of branch points ( $\mathrm{t}(9)$ $=-4.61, p<0.001)$ (Table 1). This increase was also observed in the dendritic Sholl distribution after ELS $(\mathrm{F}(1,11)=4.92, p<0.05)$ (Figure 5E). In contrast, EH did not affect the basal dendritic tree in the prelimbic cortex (Table 1, Figure 5F). In the apical tree of pyramidal neurons of the prelimbic cortex branch length, DCI, number of branch points (Table 1), and dendritic Sholl distribution (Figure 5G,5H) were not significantly altered between ELS versus control or EH versus control biAT mice.

In the cingulate cortex, apical and basal branch length, DCI, and the number of branch points did not differ significantly between ELS versus control or EH versus control biAT mice (Table 1). Also Sholl analysis of the apical and basal dendrites revealed no significant differences in dendritic distribution in this subregion after any of the early life manipulations (Figure 5I-5L).

\section{Amygdala}

Neurons of the basolateral amygdala, involved in emotional processing, have been reported to undergo substantial dendritic remodelling following stress in adult animals [28]. Indeed, we observed that ELS increased the branch length of stellate neurons in the amygdala of biAT mice $(\mathrm{t}(7)=-2.72, p<0.05)$ (Table 2), but it did not affect the number of branch points or the DCI. Sholl analysis revealed that the differences in branch length originated mainly from the distal portion of the dendritic tree $(\mathrm{F}(1,7)$ $=6.69, p<0.05$ ), which was more pronounced in ELS animals in the segments between 70 to $120 \mu \mathrm{m}$, and 150 to $160 \mu \mathrm{m}$ from the soma, whereas no differences were observed in the proximal $60 \mu \mathrm{m}$ from the soma (Figure 6A). EH did not affect dendritic morphology in the amygdala at all (Figure 6B).

\section{CA1 and CA3 of the hippocampus}

The sensitivity of the hippocampus, which is critically involved in learning and memory, of biAT mice to early life experiences was assessed in the CA1 and CA3 subregions (Figure 7A, 7F). We observed that in control and ELS-reared biAT mice, apical and basal branches of pyramidal neurons were comparable in length, in number of branch points and in DCI (Table 3). Likewise, EH did not alter hippocampal CA1 and CA3 apical and basal pyramidal dendritic morphology compared to control reared biAT mice (Table 3). Accordingly, Sholl analysis failed to reveal any effects of ELS or EH on dendritic parameters in the hippocampus of young adult biAT mice (Figure 7). 


\section{DISCUSSION}

In order to define a possible link between early life experiences and the later development of $\mathrm{AD}$, we investigated the effects of early life stress (ELS) and early handling (EH) from PND 2-9 on survival and life expectancy, on hippocampal $A \beta$ levels, on memory, and on dendritic complexity in a bigenic mouse model of $\mathrm{AD}$ with transgenic co-expression of APP.V717I and Tau.P301L (biAT mice) [21]. We report that despite the strong genetic background in this model, ELS reduced long term survival and enhanced hippocampal $A \beta$ levels at adulthood. By contrast, EH enhanced survival and reduced hippocampal A $\beta$ levels. At PND 90, the cognition of these young adult biAT mice was not affected by ELS or EH. Dendritic complexity was slightly affected in the basal branches of the $\mathrm{mPFC}$ and in the amygdala, but not in the hippocampus.

\section{Experimental model}

To examine the effect of the early life environment, pups were raised in an environment with limited nesting and bedding material from PND 2 to 9 (ELS), which induces stress in the dam and pups. In contrast, a similar group of biAT mice were exposed to daily handling for 15 minutes throughout the same period, early handling $(\mathrm{EH})$, which is known to enhance maternal care upon reunion. The body weight gain of pups from PND 2-9 was significantly decreased by ELS while significantly increased by $\mathrm{EH}$, although these differences were no longer evident at 4 months of age. The relatively mild manipulations from PND 2-9 resulted in a comparable phenotype as reported before, and validated the effectiveness of our experimental manipulation [22, 23].

We investigated transgenic mice with postnatal, neuron specific co-expression of human mutant APP.
V717I and Tau.P301L protein [21]. Both transgenes are under control of the mouse thy 1 gene promoter and become expressed in the $2^{\text {nd }}$ week postnatally, which coincided partially with the experimental PND 2-9 treatment period.

\section{Life expectancy}

A key finding of our study was that different early life experiences differentially affected life expectancy of biAT mice. We report a profound negative modulatory effect of ELS on later survival, leading to a two-fold lower life expectancy of biAT mice subjected to ELS when compared to control biAT mice. In contrast, EH significantly increased the life expectancy of the biAT mice by 1.6-fold. The juvenile age during which the mortality rate increased in the ELS group suggests a disturbed or delayed neurodevelopmental defect, which apparently is prevented by EH.

Increased early mortality is a phenomenon which has previously been observed in genetic mouse models of $\mathrm{AD}$, in particular in the more complex models. Previous studies in the current biAT mice and in the parental Tau.P301L mice with hindbrain tauopathy revealed an inverse relationship between brainstem tauopathy and lifespan [21, 29]. The brainstem controls autonomous vital systems such as breathing, swallowing, and blood pressure, suggesting that the premature death of Tau. P301L mice is caused by disturbances in these processes. However, throughout the 4 months of observation in the current study, no markedly higher number of deaths occurred in the littermates that expresses Tau.P301L only. This implies the additional and specific contribution of the APP.V717I mutant protein, possibly in combination with the tau mutation, in the early death of the biAT mice [21]. Evidence is accumulating that, similar to other models, young biAT mice are prone to epileptic activity which is
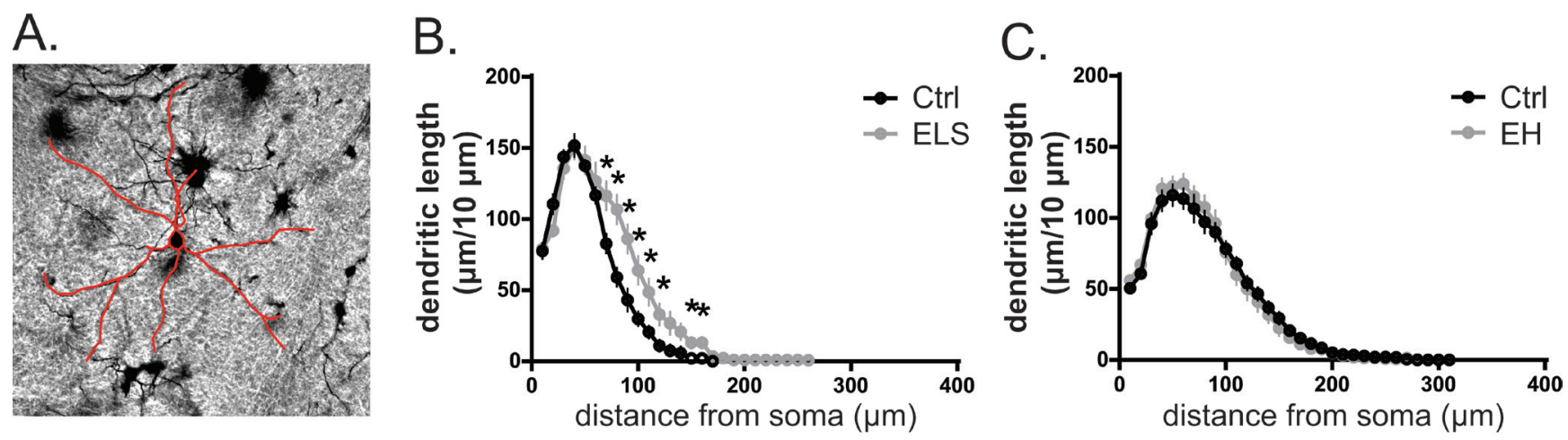

Figure 6: Early life stress increased neuronal complexity in the basolateral amygdala. A. Representative image of the basolateral nucleus of the amygdala from Golgi-Cox-stained coronal brain section. B. ELS significantly increased the segmental complexity $(\mathrm{F}(1,7)=6.69, p<0.05)$ between 70 and $120 \mu \mathrm{m}$, and between 150 and $160 \mu \mathrm{m}$ from the soma. C. Neuronal complexity was not affected by EH. Data of 3-5 neurons from one animal were averaged (3-12 animals/group) and expressed as mean \pm SEM. 

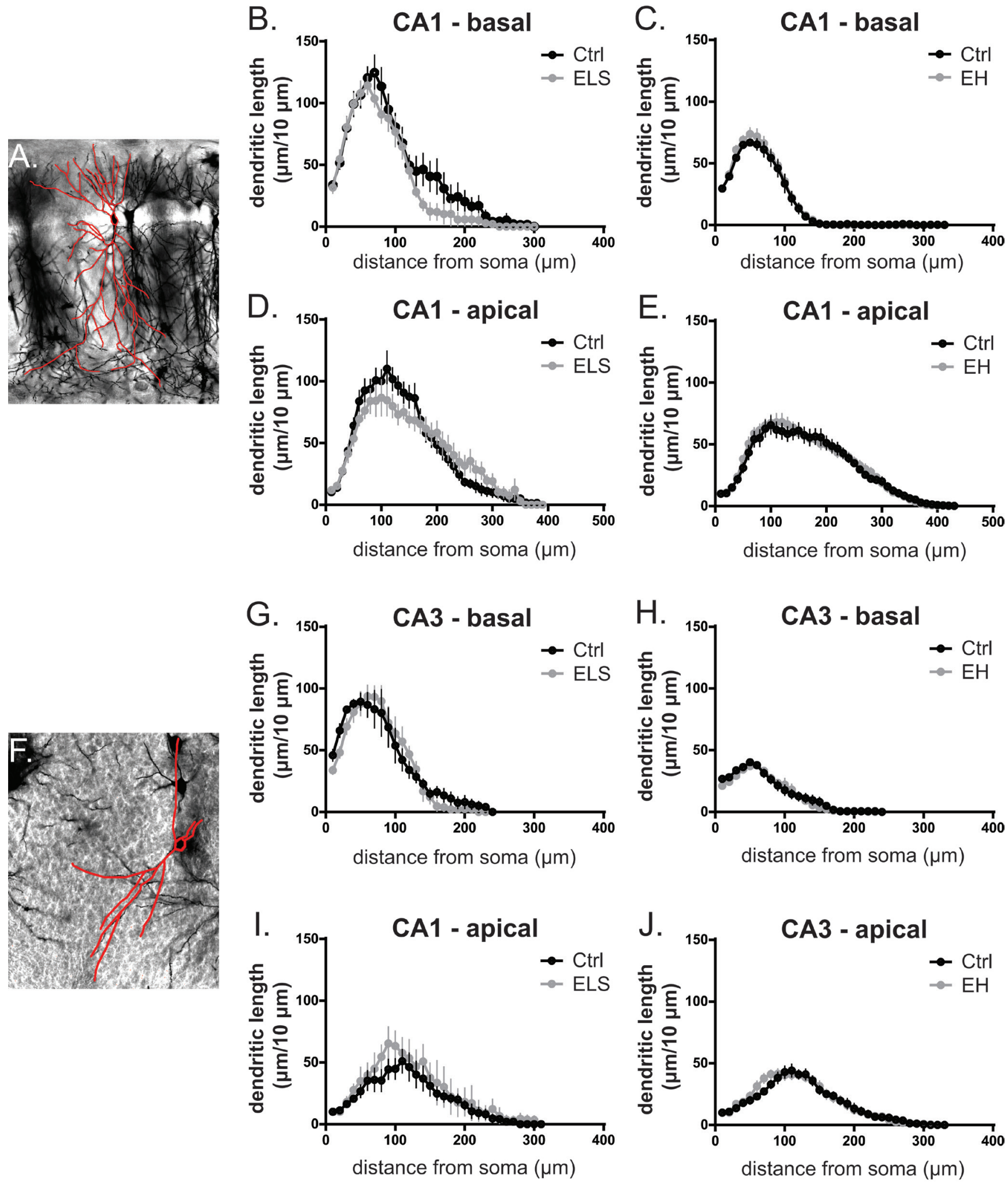

Figure 7: Neuronal morphology of CA1 and CA3 pyramidal neurons is unaffected by early life experiences. Representative images from pyramidal neurons in CA1 A. and CA3 F. areas from Golgi-Cox staining of coronal sections. Sholl plots indicated that the distribution in CA1 of basal B.,C. and apical D.,E. dendritic length at increasing distances from the centre of the cell body is comparable between groups. In the CA3, the segmental distribution of basal branches of the neuron is not affected by ELS G. and EH H.. The segmental distribution of the apical branches is also comparable between ELS and Ctrl I. and EH and Ctrl J. animals. Data from 3-5 neurons from one animal were averaged ( $n=5-12$ animals/group) and expressed as mean $\pm \operatorname{SEM}$. 
also the cause of their premature death (HM, FVL, data not shown). Indeed, different transgenic AD mouse models that express mutant forms of APP were reported to die prematurely relative to wild type mice from the same strain [30-38]. Various studies demonstrated that premature death is closely associated with spontaneous seizures and abnormal epileptiform electroencephalography (EEG) activities $[39,40]$. The implicated contribution of amyloid peptides and/or APP metabolites, alone and even more when combined with mutant protein tau [41], in inducing neuronal hyperexcitability and epilepsy susceptibility is evident. These animal model observations are consistent with the higher incidence of epileptic activity in aged AD patients as compared to non-dementing elderly [42].

Interestingly, ELS was reported in various models to elicit higher incidence of spontaneous seizures [43-46] and enhanced excitability $[47,48]$. The combined data link ELS to the observed reduced survival in biAT animals by potentiating epileptic seizures, underlined additionally by the observed enhanced $A \beta$ levels in the hippocampus of the ELS-reared biAT mice (see below). Interestingly, EH reverses this phenomenon and exerts protective effects against early mortality caused by seizure vulnerability. The combined data indicate that additional processes, besides regulation of seizure vulnerability, are modulated by positive early life experiences. Importantly, we observed that $\mathrm{EH}$ reduced the $\mathrm{A} \beta$ levels in the hippocampus, which may reduce the epileptic activity and thereby enhance life expectancy of biAT mice.

\section{Pathological biomarkers}

Although amyloid plaques and neurofibrillary tauopathy develop from 8-10 months onwards in the current bigenic model of $\mathrm{AD}$ [21], we confirmed meaningful levels of soluble $A \beta$ in the hippocampus of young adult biAT mice (4 months). In addition, phosphorylated protein tau was already evident at the same age in biAT mice. This combined biochemical and pathological profile warrants further investigations of early phase disease development, rather than end-stage disease consequences, which have been described most abundantly.

Interestingly, we observed that hippocampal soluble $\mathrm{A} \beta$ levels were further enhanced by ELS and reduced by EH in young adult biAT mice, 4 months after both the respective early life treatments. As hippocampal APP levels were unchanged, the ELS and EH treatments may affect APP-processing, respectively enhancing and inhibiting the amyloidogenic pathways. In this respect it is of interest that the promoter regions of the gene encoding $\beta$-site amyloid cleaving enzyme (BACE), which is responsible for the pathogenic cleavage of the APP protein, contains several glucocorticoid-response binding elements [49]. The activation by glucocorticoids released during stress could thereby increase amyloid peptide production in the biAT mice, and possibly in the brain of AD patients [50]. Thus, modulation of glucocorticoid levels by early life experiences could regulate BACE activity, thereby controlling post-translational processing of APP and the A $\beta$ peptide levels.

Alternatively, the enzymes that are implicated in the clearance and degradation of amyloid peptides from the brain can be involved. For instance, insulin-degrading enzyme (IDE) which degrades $A \beta$, is claimed to be dysfunctional in $\mathrm{AD}$ and contributes to its pathogenesis $[51,52]$, while IDE activity is inhibited by glucocorticoids neprilysin, which rduces $A \beta$ load, $[53,54]$. Another $A \beta$ degrading peptidase, is also regulated by glucocorticoids [55]. Finally, environmental enrichment, which is known to reduce $A \beta$ load in animals $[56,57]$ and humans $[58,59]$, also influences neprilysin levels and activity [56]. It will be interesting to determine which of these mechanisms explains the observed differential effect of ELS and EH on the $\mathrm{A} \beta$ levels in the brain of young adult biAT mice.

\section{Behaviour and dendritic morphology}

Previous studies in young adult biAT mice revealed impaired cognitive performance in the novel object recognition test, compared to wild type mice [21]. We confirm that also at 3 months of age, biAT mice successfully identified the novel object, while neither ELS nor EH modulated this capacity. Possibly, the profound effects of the transgenic background on cognition obscured any potential additional effects of ELS and EH. Alternatively, we analysed a mixed group of male and female mice, from which we know that females are more resistant to ELS than males [23]. Moreover, a potential bias could be have been introduced in our study by the fact that the most resilient animals have been studied as more vulnerable mice had already died before the test at 3 months of age. Especially in the ELS group over $60 \%$ of the original cohort could not be included in the analyses at adult age.

Following ELS, the dendritic morphology of the basolateral amygdala and prelimbic cortex was enhanced, which may be related to increased activity in these regions based on the expression of conditioned fear after early life adversity, as reported before [60-62]. In basal dendrites of the infralimbic mPFC neurons, we demonstrated a reduction in dendritic complexity both after ELS and EH. In line with our findings, the ELS paradigm reduced the dendritic complexity of the mPFC [63], although very little is known about effects of $\mathrm{EH}$ on dendritic morphology in the mPFC. In AD patients, activity in the mPFC is increased, possibly as a compensation for the decline in cognitive capacity in other brain areas [64]. While ELS decreased dendritic morphology of the mPFC, EH decreased pathological AD markers, which may make the compensatory overactivation of the $\mathrm{mPFC}$ no longer necessary, thereby potentially indirectly reducing dendritic 
morphology.

No major effects of ELS and EH were identified on the gross dendritic morphology in the CA1 and CA3 of the hippocampus, while also hippocampal PSD-95 levels were unchanged, indicating that hippocampal integrity was not further affected by ELS or EH in the biAT mice. Other studies have reported alterations in dendritic morphology in the hippocampus using the same stress paradigm [65], however, this has never before been studied in a complex transgenic AD model.

\section{Putative mechanism: HPA axis activity}

Previous findings suggest that early life adversity can lead to persistently increased HPA axis reactivity and result in enhanced glucocorticoid secretion in response to stress [22, 66, 67]. In contrast, early life enhancement persistently attenuates the stress reactivity in the adult brain by dampening HPA axis activity, resulting in reduced glucocorticoid secretion in response to stress [24]. Furthermore, stress and elevated glucocorticoid levels have been reported to increase amyloid pathology and accelerate the development of NFT in an AD mouse model [50], and such effects could be rescued by blocking glucocorticoid receptors [68]. Although this needs experimental confirmation, these studies suggest that early life experiences can accelerate or delay the appearance of AD pathology in biAT mice, possibly via changes in HPA axis activity.

There is indeed ample evidence that the HPA axis is affected in patients suffering from $\mathrm{AD}$, as reflected by markedly elevated basal levels of circulating cortisol, also in early stages of the disease $[9,69-78]$ and a failure to show cortisol suppression after a dexamethasone challenge [78-80]. Although AD patients show elevated basal cortisol levels, their HPA dysfunction did not worsen as the disease progressed, indicating that HPA axis dysfunction was mainly implicated in the early stages of the disease [9]. This suggests that in particular early alterations in HPA axis activity could contribute to the onset and possible acceleration of $\mathrm{AD}$ pathogenesis. Whether this is related to early life experiences remains to be investigated.

\section{CONCLUSION}

We report here, to our knowledge for the that exposure to early life stress significantly decreases the life expectancy in biAT mice, parallel to enhanced soluble $\mathrm{A} \beta$ levels in the hippocampus. Conversely, early handling during the same period rather increased life expectancy and reduced soluble $A \beta$ levels. Although the studied transgenic biAT mice by their very nature do not model sporadic $\mathrm{AD}$, the results do underline the importance of a modulatory role of early life experiences, superimposed on a genetic prodromal background on relevant outcome parameters of AD. Following the early life manipulations, persistent alterations in the posttranslational processing of APP may occur. While this study supports a role for early alterations in HPA axis activity in the onset of AD pathogenesis, future experiments are required to identify underlying mechanisms which may help establish more directly the causal implications of early life experiences in $\mathrm{AD}$ aetiology.

\section{MATERIALS AND METHODS}

\section{Animals}

Bigenic APP.V717I x Tau.T301P (biAT) mice, and their Tau.P301L littermates, were bred in-house by crossing male heterozygous APP.V717I mice with homozygous Tau.P301L females, all in the FVB background [21]. One male animal was housed for 2 weeks with 2 female mice. At the beginning of the third gestational week, pregnant females were housed singly. All cages were covered with filter tops to prevent extra stress to the dams, and inspected daily between 7:00 and 10:00 AM. When a new born litter was encountered that day was assigned as postnatal day 0 (PND 0). The dams and litters were left undisturbed until PND 2 and kept under standard housing conditions (1 piece of nesting material, $12 \mathrm{hr}$ light/dark cycle, lights on at 7:00 AM, humidity 40$60 \%$, temperature $21 \pm 1^{\circ} \mathrm{C}$ ) with unlimited access to food and water. All cages were also inspected daily for eventual deaths and the dates noted to draft the survival curves. In all groups, equal numbers of male and female mice were analysed. Animals were maintained and experiments were conducted in accordance with regulations of the KU Leuven and the European Community Council Directive (86/609/EC).

\section{Early life stress}

We examined how early life stress (ELS) affects survival, AD pathology, behaviour and dendritic morphology in biAT mice. Chronic ELS was induced by housing dams with limited nesting and bedding material from PND 2 to 9 [22, 23]. Dams and their litters were weighed at PND 2 and randomly assigned to the ELS or control condition. In total 7 litters were assigned to each condition, resulting in a total of 32 control mice and 28 ELS mice. Control dams were provided with normal sawdust bedding and nesting material: a square piece of cotton $5 \times 5 \mathrm{~cm}$ (Technilab-BMI, Someren, the Netherlands). The ELS dams were provided with a strongly reduced amount of sawdust bedding and half the nesting material $(2.5 \times 5 \mathrm{~cm})$ and with a fine-gauge stainless steel mesh placed $1 \mathrm{~cm}$ above the cage floor. Both 
control and ELS cages were left undisturbed until the end of the ELS regime at PND 9. Then all mice were weighed and returned to standard cages, with normal amounts of sawdust bedding and nesting material until weaning at PND 21. Tail biopsies were collected from all offspring mice for genotyping by standard PCR analysis. All animals were then housed with 2-6 same sex littermates per cage. All experimental mice were left undisturbed, except for cage cleaning once a week, until behavioural testing.

\section{Early life handling}

In a second series of experiments we examined how early handling $(\mathrm{EH})$ affects survival, AD pathology, behaviour and dendritic morphology in biAT mice. Dams and their litters were weighed at PND 2 and randomly assigned to the $\mathrm{EH}$ or control condition. In total 5 litters were assigned to the control condition and 4 litters to the $\mathrm{EH}$ condition, resulting in 15 control mice and $23 \mathrm{EH}$ mice. Control mice were housed with normal nesting and bedding material and were left undisturbed between PND 2-9. EH from PND 2-9 was induced by separating the dam and pups daily for 15 minutes between 9 AM and 11 AM. The dams and pups were placed in clean separate cages and reunited after 15 minutes in their home cage which was supplemented with 2 pieces of cotton nesting materials [24, 81]. During the separation, pups were placed on a heating pad at $32^{\circ} \mathrm{C}$. On PND 9, all mice were weighed and placed in standard cages, with sufficient bedding and nesting material until weaning at PND 21. Upon weaning, tail biopsies were collected for genotyping, and mice were housed with 2-6 same sex littermates per cage. All experimental mice were left undisturbed, except for cage cleaning once a week, until testing.

\section{Behavioural testing}

Open field: On PND 90 \pm 3 , the open field test was conducted between 8-12 AM in an empty arena (50 x $50 \mathrm{x}$ $50 \mathrm{~cm}$ ) with black walls and a translucent floor, dimly lit from underneath. Number of mice analysed: ELS vs Ctrl each $n=7$; EH vs Ctrl: $n=21$ and $n=15$ respectively. Animals were placed in a corner facing the wall, after which their exploration of the arena was monitored. The apparatus was virtually divided into an outer border and inner zone $(30 \times 30 \mathrm{~cm})$ and the time and distance spent and travelled in each zone recorded, as well as the total time and distance each mice was mobile and travelled.

Object recognition: On PND $91 \pm 3$, one day after the open field test, the mice were subjected to the novel object recognition task between $8 \mathrm{AM}$ and $4 \mathrm{PM}$, in the same arena as the open field task. The number of mice analysed: ELS vs Ctrl, $n=7$ each; EH vs Ctrl: $n=21$ and $n=15$, respectively. During the training, each mouse was granted 8 minutes to explore two identical objects (blue glass marbles, $5 \mathrm{~cm}$ diameter) placed equidistantly from the walls and each other. After 4 hours, the test trial was conducted using one original familiar object and one novel object (red plastic cube, $5 \mathrm{~cm}$ diameter) placed in exactly the same locations as during the training. Mice were reintroduced into the arena for 8 minutes to explore the novel and familiar object. The relative ratio of time spent on the novel object divided by total (novel + familiar) exploration time was used as the index. An index of over $50 \%$ preference for the novel object, was taken as recognition of the known object observed during the training trial. Mice that were immobile or spent less than $10 \mathrm{sec}$ exploring the objects were excluded from the analysis.

\section{Western blot analysis}

Western blot analysis ( $n=4 /$ group) was used to assess biochemical levels: amyloid peptides (6E10, Biolegend, lot no. 88718, 1:1000, 4 kDa), APP (6E10, Biolegend, lot no. 88718, 1:1000, $100 \mathrm{kDa}$ ), PSD-95 (D27E11, Cell Signalling, lot no. 23450S, 1:1000, 95 $\mathrm{kDa}$ ), phosphorylated tau (AT8, Thermo Scientific, 1:200, $79 \mathrm{kDa}$ ), and GADPH (14C10, Cell Signalling, lot no. $36835,1: 3000,37 \mathrm{kDa})$. Protein brain extracts were prepared following rapid decapitation from one hemisphere which was snap frozen and stored on -80 ${ }^{\circ} \mathrm{C}$ until processing. Hippocampi were dissected and homogenised in RIPA buffer (150 mM NaCl, 1\% NP-40, $0.5 \%$ sodium deoxycholate, $0.1 \% \mathrm{SDS}, \mathrm{pH}=6.8)$ using small pellet mixers, then incubated for $10 \mathrm{~min}$ at room temperature and subsequently sonicated for $2 \times 30 \mathrm{sec}$ at maximum intensity, again incubated for $10 \mathrm{~min}$ and then centrifuged $\left(1 \mathrm{~min}, 10000 \mathrm{xg}, 4^{\circ} \mathrm{C}\right)$. The supernatants were collected and the protein concentrations determined by a BCA Protein Assay (Pierce, The Netherlands). An aliquot equivalent to $15 \mu \mathrm{g}$ protein was separated by electrophoresis on $12.5 \%$ polyacrylamide-SDS gels with 5\% stacking gels and proteins transferred to PVDF membranes for 2 hours at $75 \mathrm{~V}$ in Towbin buffer (25 $\mathrm{mM}$ Tris, $192 \mathrm{mM}$ glycine, 20\% methanol, $\mathrm{pH}=8.3$ ). The membranes were blocked with TBST (TBS $+0.1 \%$ Tween-20) containing 5\% BSA for 1 hour, rinsed in TBST and strips were incubated with primary antibody overnight at $4^{\circ} \mathrm{C}$. Blots were washed with TBST and incubated for 2 hours with secondary antibody. After thorough washing with TBS, signal was developed (Licor Odyssey FC; Leusden, the Netherlands). Signal intensities were measured using dedicated software (ImageJ; NIH; Bethesda) and normalised against GADPH as internal marker. Individual protein levels were calculated as the mean of 3 independent replications. 


\section{Dendritic morphology}

Golgi-Cox impregnation was performed as described previously [82]. Immediately after decapitation, one hemisphere was immersed in Golgi-Cox solution (5\% $\mathrm{K} 2 \mathrm{CrO} 4,5 \% \mathrm{HgCL}$ and 5\% $\mathrm{K} 2 \mathrm{Cr} 2 \mathrm{O} 7)$ for 14 days, after which they were embedded in celloidine and cut coronally into $200 \mu \mathrm{m}$ thick sections. The dendritic tree of neurons in the amygdala (bregma $-2.0 \mathrm{~mm}$ to $-3.2 \mathrm{~mm}$ ), the CA1 and CA3 area of the hippocampus (bregma -2.0 $\mathrm{mm}$ to $-3.2 \mathrm{~mm}$ ), and the IL, PRL, and CG of the mPFC (bregma $2.2 \mathrm{~mm}$ to $4.2 \mathrm{~mm}$ ) were analysed by obtaining Z-stacks (step-size $1 \mu \mathrm{m}$ ) using a microscope (LSM510, Zeiss, Germany) with a 20x magnification. Cells were reconstructed using dedicated software (Image Pro Analysis and Neurodraw reconstruction). Neurons were included according to criteria as previously described [28, 83]: (1) the presence of untruncated dendrites, (2) consistent and dark impregnation along the entire extent of all dendrites, and (3) relative isolation from neighbouring impregnated neurons. A total of 3-5 neurons from each animal were averaged (3-12 animals/group). Structural measures included total branch length, number of branch points, and dendritic complexity index (DCI). The DCI was calculated by the formula: $\left(\sum\right.$ branchtip orders $+\#$ of branch tips)/(\# of primary dendrites) x (total arbour length). In addition, for each reconstructed neuron, the 3D Sholl analysis was performed using dedicated software (NeuronStudio) [84].

\section{Statistical analysis}

Statistical analysis was performed using SPSS 21.0 except for outlier analysis, which was conducted using Grubb's test (Graphpad Prism 5). All data are presented as mean \pm SEM, with $p<0.05$ considered statistically significant. All experimental groups were compared to their respective control group.

Analysis of mouse survival was conducted using the log rank test. Body weight and behaviour were analysed using an independent samples $t$-test, or by the non-parametric equivalent Mann Whitney $U$ test if one of its assumptions was violated. Data from the novel object recognition test were analysed by onesample $t$-test to compare the exploration percentage to 50 (no discrimination). For the analysis of the dendritic morphology, 3 to 5 neurons from one animal were averaged and compared using independent samples $t$-test. Statistical significances for segmental dendritic plots (Sholl analysis) were obtained from repeated measures ANOVA with adequate corrections (Greenhouse-Geisser) on the significant values when the sphericity assumption was not met, and post hoc $t$-test was conducted to determine the distance at which differences occurred.

\section{ACKNOWLEDGMENTS}

The authors thank Benoit Lechat for assistance with the experimental animal work, Gideon Meerhoff and Jan den Blaauwen for their technical support with the preparation of the Golgi-Cox staining, and Judith Kok, Amber Brands, Nicole Breeuwsma, and Mariska Willemsen for their contribution to the analysis of the brain tissue. This study was supported by a grant from The Internationale Stichting voor Alzheimer Onderzoek (ISAO, grant \#12534). PJL is supported by NWO, the ISAO and by Alzheimer Nederland.

\section{CONFLICTS OF INTERESTS}

The authors declare no actual or potential conflicts of interests.

\section{REFERENCES}

1. Selkoe DJ, and Schenk D. Alzheimer's disease: molecular understanding predicts Amyloid-based therapeutics. Annu Rev Pharmacol Toxicol. 2003; 43:545-584.

2. Braak H, and Braak E. Evolution of the neuropathology of Alzheimer's disease. Acta Neurol Scand Suppl. 1996; 165:3-12.

3. Sydow A, Van der Jeugd A, Zheng F, Ahmed T, Balschun D, Petrova O, Drexler D, Zhou L, Rune G, Mandelkow E, D’Hooge R, Alzheimer C, and Mandelkow EM. Tauinduced defects in synaptic plasticity, learning, and memory are reversible in transgenic mice after switching off the toxic tau mutant. J Neurosci. 2011; 31:2511-2525.

4. Hsia AY, Masliah E, McConlogue L, Yu G, Tatsuno G, Hu K, Kholodenko D, Malenka RC, Nicoll RA, and Mucke L. Plaque-independent disruption of neural circuits in Alzheimer's disease mouse models. Proc Natl Acad Sci U S A. 1999; 96:3228-33.

5. Campion D, Dumanchin C, Hannequin D, Dubois B, Belliard S, Puel M, Thomas-Anterion C, Michon A, Martin C, Charbonnier F, Raux G, Camuzat A, Penet C, et al. Early-onset autosomal dominant Alzheimer disease: prevalence, genetic heterogeneity, and mutation spectrum. Am J Hum Genet. 1999; 65:664-670.

6. Travis J. New piece in Alzheimer's puzzle. Science. 1993; 261:828-9.

7. Satizabal C, Beiser A, Chouraki V, Chêne G, Dufouil C, and Seshadri S. Incidence of dementia over three decades in the Framingham Heart study. N Engl J Med. 2016; 374:523532.

8. Popp J, Wolfsgruber S, Heuser I, Peters O, Hüll M, Schröder J, Möller H, Lewczuk P, Schneider A, Jahn H, Luckhaus C, Perneczky R, Frölich L, et al. Cerebrospinal fluid cortisol and clinical disease progression in $\mathrm{MCI}$ and dementia of Alzheimer's type. Neurobiol Aging. 2015; 
36:601-607.

9. Swanwick GRJ, Kirby M, Bruce I, Buggy F, Coen RF, Coakley D, and Lawlor B. Hypothalamic-pituitary-adrenal axis dysfunction in Alzheimer's disease: Lack of association between longitudinal and cross-sectional findings. Am J Psychiatry. 1998; 155:286-289.

10. Wilson RS, Barnes LL, Bennett DA, Li Y, Bienias JL, Mendes de Leon CF, and Evans DA. Proneness to psychological distress and risk of Alzheimer disease in a biracial community. Neurology. 2005; 64:380-2.

11. Carroll JC, Iba M, Bangasser DA, Valentino RJ, James MJ, Brunden KR, Lee VMY, and Trojanowski JQ. Chronic stress exacerbates tau pathology, neurodegeneration, and cognitive performance through a corticotropin-releasing factor receptor-dependent mechanism in a transgenic mouse model of tauopathy. J Neurosci. 2011; 31:14436-14449.

12. Jeong YH, Park CH, Yoo J, Shin KY, Ahn S, Kim H, Lee $\mathrm{SH}$, Emson PC, and Suh Y. Chronic stress accelerates learning and memory impairments and increases amyloid deposition in APPV717I-CT100 transgenic mice, an Alzheimer's disease model. FASEB J. 2006; 20:729-731.

13. Lee J, and Han P. An update of animal models of Alzheimer disease with a reevaluation of plaque depositions. Exp Neurobiol. 2013; 22:84-95.

14. Meaney M, Aitken D, van Berkel C, Bhatnagar S, and Sapolsky R. Effect of neonatal handling on age-related impairments associated with the hippocampus. Science. 1988; 239:766-8.

15. Brunson KL. Mechanisms of late-onset cognitive decline after early-life stress. J Neurosci. 2005; 25:9328-9338.

16. Enthoven L, Oitzl M, Koning N, Van Der Mark M, and De Kloet E. Hypothalamic-pituitary-adrenal axis activity of newborn mice rapidly desensitizes to repeated maternal absence but becomes highly responsive to novelty. Endocrinology. 2008; 149:6366-6377.

17. Meijer OC, Topic B, Steenbergen PJ, Jocham G, Huston JP, and Oitzl MS. Correlations between hypothalamuspituitary-adrenal axis parameters depend on age and learning capacity. Endocrinology. 2005; 146:1372-1381.

18. Chen Y, and Baram TZ. Toward understanding how early-life stress reprograms cognitive and emotional brain networks. Neuropsychopharmacology. 2016; 41:197-206.

19. Nemeroff CB. Paradise lost: The neurobiological and clinical consequences of child abuse and neglect. Neuron. 2016; 89:892-909.

20. Cañete T, Blázquez G, Tobeña A, Giménez-Llort L, and Fernández-Teruel A. Cognitive and emotional alterations in young Alzheimer's disease (3xTgAD) mice: Effects of neonatal handling stimulation and sexual dimorphism. Behav Brain Res. 2015; 281:156-171.

21. Terwel D, Muyllaert D, Dewachter I, Borghgraef P, Croes $\mathrm{S}$, Devijver H, and Van Leuven F. Amyloid activates GSK$3 \beta$ to aggravate neuronal tauopathy in bigenic mice. Am J Pathol. 2008; 172:786-98.
22. Rice CJ, Sandman CA, Lenjavi MR, and Baram TZ. A novel mouse model for acute and long-lasting consequences of early life stress. Endocrinology. 2008; 149:4892-900.

23. Naninck EFG, Hoeijmakers L, Kakava-Georgiadou N, Meesters A, Lazic SE, Lucassen PJ, and Korosi A. Chronic early life stress alters developmental and adult neurogenesis and impairs cognitive function in mice. Hippocampus. 2015; 25:309-328.

24. Avishai-Eliner S, Eghbal-Ahmadi M, Tabachnik E, Brunson KL, and Baram TZ. Down-regulation of hypothalamic corticotropin-releasing hormone messenger ribonucleic acid (mRNA) precedes early-life experience-induced changes in hippocampal glucocorticoid receptor mRNA. Endocrinology. 2001; 142:89-97.

25. Plotsky P, and Meaney M. Early, postnatal experience alters hypothalamic corticotropin-releasing factor (CRF) mRNA, median eminence CRF content and stress-induced release in adult rats. Brain Res Mol Brain Res. 1993; 18:195-200.

26. Chocyk A, Bobula B, Dudys D, Przyborowska A, MajcherMaślanka I, Hess G, and Wedzony K. Early-life stress affects the structural and functional plasticity of the medial prefrontal cortex in adolescent rats. Eur J Neurosci. 2013; 38:2089-2107.

27. Sotres-Bayon F, and Quirk GJ. Prefrontal control of fear: more than just extinction. Curr Opin Neurobiol. 2010; 20:231-235.

28. Vyas A, Mitra R, Shankaranarayana Rao B, and Chattarji S. Chronic stress induces contrasting patterns of dendritic remodeling in hippocampal and amygdaloid neurons. J Neurosci. 2002; 22:6810-6818.

29. Terwel D, Lasrado R, Snauwaert J, Vandeweert E, Van Haesendonck C, Borghgraef P, and Van Leuven F. Changed conformation of mutant Tau-P301L underlies the moribund tauopathy, absent in progressive, nonlethal axonopathy of tau-4R/2N transgenic mice. J Biol Chem. 2005; 280:39633973.

30. King DL, and Arendash GW. Behavioral characterization of the $\mathrm{Tg} 2576$ transgenic model of Alzheimer's disease through 19 months. Physiol Behav. 2002; 75:627-642.

31. Lewis HD, Beher D, Smith D, Hewson L, Cookson N, Reynolds DS, Dawson GR, Jiang M, Van Der Ploeg LH, Qian S, Rosahl TW, Kalaria RN, and Shearman MS. Novel aspects of accumulation dynamics and $A \beta$ composition in transgenic models of AD. Neurobiol Aging. 2004; 25:11751185.

32. Kim J, Onstead L, Randle S, Price R, Smithson L, Zwizinski C, Dickson DW, Golde T, and McGowan E. A $\beta 40$ inhibits amyloid deposition in vivo. J Neurosci. 2007; 27:627-633.

33. Gimbel DA, Nygaard HB, Coffey EE, Gunther EC, Lauren J, Gimbel ZA, and Strittmatter SM. Memory impairment in transgenic Alzheimer mice requires cellular prion protein. $\mathrm{J}$ Neurosci. 2010; 30:6367-6374.

34. Moechars D, Lorent K, and Van Leuven F. Premature death in transgenic mice that overexpress a mutant amyloid 
precursor protein is preceded by severe neurodegeneration and apoptosis. Neuroscience. 1999; 91:819-30.

35. Hsiao KK, Borchelt DR, Oison K, Johannsdottir R, Kitt C, Yunis W, Xu S, Eckman C, Younkin S, Price D, Clark $\mathrm{HB}$, and Carlsonll G. Age-related CNS disorder and early death in transgenic FVB/N mice overexpressing Alzheimer Amyloid Precursor Proteins. Neuron. 1995; 15:1203-1218.

36. Carlson GA, Borchelt DR, Dake A, Turner S, Danielson V, Coffin JD, Eckman C, Meiners J, Nilsen SP, Younkin $\mathrm{SG}$, and Hsiao KK. Genetic modification of the phenotypes produced by amyloid precursor protein overexpression in transgenic mice. Hum Mol Genet. 1997; 6:1951-9.

37. LaFerla F, Tinkle B, Bieberich C, Haudenschild C, and Jay $\mathrm{G}$. The Alzheimer's A $\beta$ peptide induces neurodegeneration and apoptotic cell death in transgenic mice. Nat Genet. 1995; 9:21-30.

38. Westmark C, Westmark P, Beard A, Hildebrandt S, and Malter J. Seizure susceptibility and mortality in mice that over-express amyloid precursor protein. Int J Clin Exp Pathol. 2008; 1:157-168.

39. Minkeviciene R, Rheims S, Dobszay MB, Zilberter M, Hartikainen J, Fulop L, Penke B, Zilberter Y, Harkany T, Pitkanen A, and Tanila H. Amyloid-induced neuronal hyperexcitability triggers progressive epilepsy. J Neurosci. 2009; 29:3453-3462.

40. Palop JJ, Chin J, Roberson ED, Wang J, Thwin MT, BienLy N, Yoo J, Ho KO, Yu G, Kreitzer A, Finkbeiner S, Noebels JL, and Mucke L. Aberrant excitatory neuronal activity and compensatory remodeling of inhibitory hippocampal circuits in mouse models of Alzheimer's disease. Neuron. 2007; 55:697-711.

41. Maeda S, Djukic B, Taneja P, Yu G, Lo I, Davis A, Craft R, Guo W, Wang X, Kim D, Ponnusamy R, Gill TM, and Masliah E. Expression of A 152 T human tau causes agedependent neuronal dysfunction and loss in transgenic mice. EMBO Rep. 2016; 17:530-51. doi: 10.15252/ embr.201541438.

42. Larner AJ. Epileptic seizures in AD patients. NeuroMolecular Med. 2010; 12:71-77.

43. Kazl C, Foote L, Kim M, and Koh S. Early-life experience alters response of developing brain to seizures. Brain Res. 2009; 1285:174-181.

44. Kumar G, Jones NC, Morris MJ, Rees S, O'Brien TJ, and Salzberg MR. Early life stress enhancement of limbic epileptogenesis in adult rats: mechanistic insights. PLoS One. 2011; 6:e24033.

45. Salzberg M, Kumar G, Supit L, and Jones N. Early postnatal stress confers enduring vulnerability to limbic epileptogenesis. Epilepsia. 2007; 48:2079-85.

46. Huang L. Early-life stress impacts the developing hippocampus and primes seizure occurrence: cellular, molecular, and epigenetic mechanisms. Front Mol Neurosci. 2014; 7:1-15.
47. Renthal W, Maze I, Krishnan V, Covington HE, Xiao G, Kumar A, Russo SJ, Graham A, Tsankova N, Kippin TE, Kerstetter KA, Neve RL, Haggarty SJ, et al. Histone deacetylase 5 epigenetically controls behavioral adaptations to chronic emotional stimuli. Neuron. 2007; 56:517-29.

48. Dubé CM, Molet J, Singh-Taylor A, Ivy A, Maras PM, and Baram TZ. Hyper-excitability and epilepsy generated by chronic early-life stress. Neurobiol Stress. 2015; 2:10-19.

49. Sambamurti K, Kinsey R, Maloney B, Ge Y, and Lahiri D. Gene structure and organization of the human $\beta$-secretase (BACE) promoter. FASEB J. 2004; 18:1034-6.

50. Green K, Billings L, Roozendaal B, McGaugh J, and LaFerla F. Glucocorticoids increase Amyloid- $\beta$ and tau pathology in a mouse model of Alzheimer's disease. J Neurosci. 2006; 26:9047-9056.

51. Qiu WQ, Walsh DM, Ye Z, Vekrellis K, Zhang J, Podlisny MB, Rosner MR, Safavi A, Hersh LB, and Selkoe DJ. Insulin-degrading enzyme regulates extracellular levels of amyloid $\beta$-protein by degradation. J Biol Chem. 1998; 273:32730-8.

52. Vekrellis K, Ye Z, Qiu WQ, Walsh D, Hartley D, Chesneau V, Rosner MR, and Selkoe DJ. Neurons regulate extracellular levels of amyloid $\beta$-protein via proteolysis by insulin-degrading enzyme. J Neurosci. 2000; 20:1657-1665.

53. Harada S, Smith R, Hu D, and Jarett L. Dexamethasone inhibits insulin binding to insulin-degrading enzyme and cytosolic insulin-binding protein p82. Biochem Biophys Res Commun. 1996; 218:154-158.

54. Kulstad JJ, McMillan PJ, Leverenz JB, Cook DG, Green PS, Peskind ER, Wilkinson CW, Farris W, Mehta PD, and Craft S. Effects of chronic glucocorticoid administration on insulin-degrading enzyme and amyloid- $\beta$ peptide in the aged macaque. J Neuropathol Exp Neurol. 2005; 64:139146.

55. van der Velden VH. Glucocorticoids: mechanisms of action and anti-inflammatory potential in asthma. Mediators Inflamm. 1998; 7:229-37.

56. Lazarov O, Robinson J, Tang YP, Hairston IS, KoradeMirnics Z, Lee VMY, Hersh LB, Sapolsky RM, Mirnics $\mathrm{K}$, and Sisodia SS. Environmental enrichment reduces A $\beta$ levels and amyloid deposition in transgenic mice. Cell. 2005; 120:701-713.

57. Adlard PA. Voluntary Exercise decreases Amyloid load in a transgenic model of Alzheimer's disease. J Neurosci. 2005; 25:4217-4221.

58. Rovio S, Kåreholt I, Helkala E, Viitanen M, Winblad B, Tuomilehto J, Soininen H, Nissinen A, and Kivipelto M. Leisure-time physical activity at midlife and the risk of dementia and Alzheimer's disease. Lancet Neurol. 2005; 4:705-11.

59. Podewils LJ, Guallar E, Kuller LH, Fried LP, Lopez OL, Carlson M, and Lyketsos CG. Physical activity, APOE genotype, and dementia risk: Findings from the 
cardiovascular health cognition study. Am J Epidemiol. 2005; 161:639-651.

60. Vidal-Gonzalez I, Vidal-Gonzalez B, Rauch S, and Quirk G. Microstimulation reveals opposing influences of prelimbic and infralimbic cortex on the expression of conditioned fear. Learn Mem. 2006; 13:728-733.

61. Diehl LA, Pereira NDSC, Laureano DP, Benitz AND, Noschang C, Ferreira AGK, Scherer EB, Machado FR, Henriques TP, Wyse ATS, Molina V, and Dalmaz C. Contextual fear conditioning in maternal separated rats: The amygdala as a site for alterations. Neurochem Res. 2014; 39:384-393.

62. Rosenkranz JA, and Grace AA. Cellular mechanisms of infralimbic and prelimbic prefrontal cortical inhibition and dopaminergic modulation of basolateral amygdala neurons in vivo. J Neurosci. 2002; 22:324-337.

63. Yang X, Liao X, Uribe-Mariño A, Liu R, Xie X, Jia J, Su Y, Li J, Schmidt M, Wang X, and Si T. Stress during a critical postnatal period induces region-specific structural abnormalities and dysfunction of the prefrontal cortex via CRF1. Neuropsychopharmacology. 2015:1203-1215.

64. Grady CL, McIntosh AR, Beig S, Keightley ML, Burian H, and Black SE. Evidence from functional neuroimaging of a compensatory prefrontal network in Alzheimer's disease. J Neurosci. 2003; 23:986-993.

65. Liu R, Yang X, Liao X, and Xie X. Early postnatal stress suppresses the developmental trajectory of hippocampal pyramidal neurons: the role of CRHR1. Brain Struct Funct. 2016:1-12.

66. Meaney M. Maternal care, gene expression, and the transmission of individual differences in stress reactivity across generations. Annu Rev Neurosci. 2001; 24:1161-92.

67. Martisova E, Aisa B, Guerenu G, and Ramirez M. Effects of early maternal separation on biobehavioral and neuropathological markers of Alzheimer's disease in adult male rats. Curr Alzheimer Res. 2013; 10:420-32.

68. Lanté F, Chafai M, Raymond EF, Pereira ARS, Mouska X, Kootar S, Barik J, Bethus I, and Marie H. Subchronic glucocorticoid receptor inhibition rescues early episodic memory and synaptic plasticity deficits in a mouse model of Alzheimer's disease. Neuropsychopharmacology. 2015; 40:1772-81.

69. Davis KL, Davis BM, Greenwald BS, Mohs RC, Mathé AA, Johns CA, and Horvath TB. Cortisol and Alzheimer's disease. I: Basal studies. Am J Psychiatry. 1986; 143:300305.

70. Czech C, Berndt P, Busch K, Schmitz O, Wiemer J, Most V, Hampel H, Kastler J, and Senn H. Metabolite profiling of Alzheimer's disease cerebrospinal fluid. PLoS One. 2012; 7.

71. Masugi F, Ogihara T, Sakaguchi K, Otsuka A, Tsuchiya Y, Morimoto S, Kumahara Y, Saeki S, and Nishide M. High plasma levels of cortisol in patients with senile dementia of the Alzheimer's type. Methods Find Exp Clin Pharmacol. 1989; 11:707-10.

72. Rasmuson S, Näsman B, Carlström $\mathrm{K}$, and Olsson $\mathrm{T}$. Increased levels of adrenocortical and gonadal hormones in mild to moderate Alzheimer's disease. Dement Geriatr Cogn Disord. 2002; 13:74-79.

73. Elgh E, Lindqvist Astot A, Fagerlund M, Eriksson S, Olsson $\mathrm{T}$, and Näsman B. Cognitive dysfunction, hippocampal atrophy and glucocorticoid feedback in Alzheimer's disease. Biol Psychiatry. 2006; 59:155-61.

74. Rasmuson S, Andrew R, Näsman B, Seckl JR, Walker BR, and Olsson $\mathrm{T}$. Increased glucocorticoid production and altered cortisol metabolism in women with mild to moderate Alzheimer's disease. Biol Psychiatry. 2001; 49:547-552.

75. Rasmuson S, Nasman B, Eriksson S, Carlstrom K, and Olsson T. Adrenal responsivity in normal aging and mild to moderate Alzheimer's disease. Biol Psychiatry. 1998; 43:401-407.

76. Näsman B, Olsson T, Fagerlund M, Eriksson S, Viitanen $\mathrm{M}$, and Carlström K. Blunted adrenocorticotropin and increased adrenal steroid response to human corticotropinreleasing hormone in Alzheimer's disease. Biol Psychiatry. 1996; 39:311-318.

77. Seckl JR, and Olsson T. Glucocorticoid hypersecretion and the age-impaired hippocampus: Cause or effect? J Endocrinol. 1995; 145:201-211.

78. Näsman B, Olsson T, Viitanen M, and Carlstrom K. A subtle disturbance in the feedback regulation hypothalamicpituitary-adrenal axis in the early phase of Alzheimer's disease. Psychoneuroendocrinology. 1995; 20:211-220.

79. Molchan SE, Hill JL, Mellow AM, Lawlor BA, Martinez $\mathrm{R}$, and Sunderland $\mathrm{T}$. The dexamethasone suppression test in Alzheimer's disease and major depression: relationship to dementia severity, depression, and CSF monoamines. Int Psychogeriatr. 1990; 2:99-122.

80. Greenwald BS, Mathé AA, Mohs RC, Levy M, Johns CA, and Davis KL. Cortisol and Alzheimer's disease, II: Dexamethasone suppression, dementia severity, and affective symptoms. Am J Psychiatry. 1986; 143:442-446.

81. Millstein RA, and Holmes A. Effects of repeated maternal separation on anxiety- and depression-related phenotypes in different mouse strains. Neurosci Biobehav Rev. 2007; 31:3-17.

82. Oomen CA, Soeters H, Audureau N, Vermunt L, van Hasselt FN, Manders EMM, Joëls M, Lucassen PJ, and Krugers H. Severe early life stress hampers spatial learning and neurogenesis, but improves hippocampal synaptic plasticity and emotional learning under high-stress conditions in adulthood. J Neurosci. 2010; 30:6635-45.

83. Champagne D, Bagot R, van Hasselt F, Ramakers G, Meaney M, de Kloet E, Joëls M, and Krugers H. Maternal care and hippocampal plasticity: evidence for experiencedependent structural plasticity, altered synaptic functioning, 
and differential responsiveness to glucocorticoids and stress. J Neurosci. 2008; 28:6037-45.

84. Wearne SL, Rodriguez A, Ehlenberger DB, Rocher AB, Henderson SC, and Hof PR. New techniques for imaging, digitization and analysis of three-dimensional neural morphology on multiple scales. Neuroscience. 2005; 136:661-680. 